\title{
A análise da comercialização institucional da agricultura familiar via Pnae no Território Rural Médio Araguaia, Goiás: possibilidades e limites da abordagem da nova economia institucional
}

\author{
The analysis of the institutional commercialization of family agriculture via \\ Pnae in the Médio Araguaia Rural Territory, Goiás: possibilities and limits of the \\ approach of the new institutional economics
}

\section{El análisis de la comercialización institucional de la agricultura familiar via Pnae en el Territorio Rural Medio Araguaia, Goiás: posibilidades y límites del enfoque de la nueva economía institucional}

\author{
Fernanda Chaveiro da Silva ${ }^{1}$ \\ Thiago de Carvalho Verano ${ }^{1}$ \\ Cleyzer Adrian da Cunha ${ }^{1}$ \\ Alcido Eleonor Wander ${ }^{1}$
}

Recebido em 13/06/2018; revisado e aprovado em 02/10/2018; aceito em 30/07/2020.

DOI: http://dx.doi.org/10.20435/inter.v21i4.2046

\begin{abstract}
Resumo: Sob o enfoque das teorias da Nova Economia Institucional (NEI), o presente trabalho tem por objetivo verificar a inserção comercial da agricultura familiar no Programa Nacional de Alimentação Escolar (Pnae), no Território Rural Médio Araguaia, Goiás (GO), com a finalidade de se compreender até que ponto a NEl é útil para se entender as questões e peculiaridades que envolvem os agricultores familiares. Por meio do método dialético, da pesquisa bibliográfica e dos dados obtidos a partir da porcentagem de aquisição da agricultura familiar via Pnae dos 21 (vinte e um) municípios do Território Médio Araguaia, GO, através das sedes das subsecretarias estaduais de educação nos municípios de Iporá, Piranhas e Jussara, nos anos de 2014 e 2015, foi possível verificar o comportamento dos agentes e dos agricultores envolvidos no Pnae, demonstrando como a racionalidade limitada e o oportunismo dos agentes, a assimetria de informação entre e dentro das organizações, os custos de transação, a especificidade dos ativos, os contratos e a estrutura de governança podem ajudar a compreender e explicar os processos econômicos dos agricultores familiares. Assim, verificou-se que as políticas públicas de assessoria às organizações da agricultura familiar, como o Núcleo de Extensão em Desenvolvimento Territorial (Nedet), são importantes para a efetivação da inclusão produtiva dos agricultores familiares, podendo ainda problematizar as transações com uma maior precisão ao analisá-las com foco na teoria sustentada pela NEI, embora a lógica produtiva dos agricultores familiares não se concentre apenas no viés econômico.
\end{abstract}

Palavras-chave: agricultores familiares; Pnae; Nova Economia Institucional.

Abstract: Focusing on the New Institutional Economics (NEI) theories, the objective of this study is to verify the commercial insertion of family agriculture in the National School Feeding Program (Pnae) in the Médio Araguaia Rural Territory, Goiás (GO), in order to comprehend to what extent the NEl is useful for understanding the issues and peculiarities that involve family farmers. Through the dialectical method, the bibliographical research, and the data obtained from the percentage of acquisition of family agriculture via the 21 (twentyone) municipalities of the Médio Araguaia Territory, GO, through the headquarters of the state education sub-secretaries in the municipalities of Iporá, Piranhas and Jussara, in the years 2014 and 2015, it was possible to verify the behavior of agents and farmers involved in the Pnae, demonstrating how the limited rationality and opportunism of agents, the asymmetry of information between and within organizations, the costs the specificity of assets, contracts, and the governance structure can help to understand and explain the economic processes of family farmers. Thus, we verified that the public policies of assistance to family agriculture organizations, such as the Extension Nucleus for Territorial Development (Nedet), are important for the effective inclusion of family farmers, and can also problematize transactions with more accuracy in analyzing them with a focus on the theory supported by the NEI, although the productive logic of family farmers does not focus only on the economic bias.

\footnotetext{
${ }^{1}$ Universidade Federal de Goiás (UFG), Goiânia, Goiás, Brasil.
} 
Keywords: family farmers; Pnae; New Institutional Economics.

Resumen: En el enfoque de las teorías de la Nueva Economía Institucional (NEI), el presente trabajo tiene por objetivo verificar la inserción comercial de la agricultura familiar en el Programa Nacional de Alimentación Escolar (Pnae) en el Territorio Rural Medio Araguaia, Goiás (GO), con la finalidad de comprender hasta qué punto la NEI es útil para se entiende las cuestiones y peculiaridades que involucra a los agricultores familiares. Por medio del método dialéctico, de la investigación bibliográfica y de los datos obtenidos a partir del porcentaje de adquisición de la agricultura familiar vía Pnae de los 21 (veinte y uno) municipios del Territorio Medio Araguaia, GO, a través de las sedes de las subsecretarias estatales de educación en los municipios de I porá, Piranhas y Jussara, en los años 2014 y 2015, fue posible verificar el comportamiento de los agentes y de los agricultores involucrados en el Pnae, demostrando cómo la racionalidad limitada y el oportunismo de los agentes, la asimetría de información entre y dentro de las organizaciones, los costos de la transacción, la especificidad de los activos, los contratos y la estructura de gobernanza pueden ayudar a comprender y explicar los procesos económicos de los agricultores familiares. Así, se verificó que las políticas públicas de asesoría a las organizaciones de la agricultura familiar, como el Núcleo de Extensión en Desarrollo Territorial (Nedet), son importantes para la efectividad de la inclusión productiva de los agricultores familiares, pudiendo aún problematizar las transacciones con una mayor precisión al analizarlas con foco en la teoría sustentada por la NEl, aunque la lógica productiva de los agricultores familiares no se concentre sólo en el sesgo económico.

Palabras clave: agricultores familiares; Pnae; Nueva Economía Institucional.

\section{INTRODUÇÃO}

Atualmente, pode-se considerar que o campo brasileiro abrange dois distintos modelos de desenvolvimento rural: o agronegócio e a agricultura familiar (AF). O primeiro foi difundido no Brasil a partir da década de 1960 e tinha como finalidade aumentar a produção e produtividade agrícola, baseando-se no cultivo de monoculturas, no uso intensivo de tecnologias, canalizadas prioritariamente por incentivos estatais. Já o segundo começou a se consolidar no final da década de 1980, início da década de 1990, por meio das críticas ao modelo dominante da modernização produtivista da agricultura.

Antes da década de 1990, a própria referência à agricultura familiar era quase inexistente no país, sendo os termos pequeno produtor, produtor de subsistência ou de baixa renda usualmente utilizados para identificar e qualificar essa categoria social. Com a Constituição Federal de 1988, foi possível incorporar dispositivos legais que traduziram o reconhecimento de outras formas sociais, inspirando novas políticas de apoio a esta categoria (WANDERLEY, 2017).

Baseada na associação entre trabalho, família e produção, a agricultura familiar brasileira representa o setor numericamente majoritário no campo. Dados do Censo Agropecuário do Instituto Brasileiro de Geografia e Estatística (IBGE) mostram que, em 2006, o país tinha um total de 5.175.489 estabelecimentos agropecuários, dos quais 4.367.902 poderiam ser classificados como agricultores familiares, o que representa cerca de $84 \%$ do total de estabelecimentos (IBGE, 2009).

Além de serem significativamente representativos, estudos já realizados mostram o potencial dos agricultores familiares. Segundo Heberlê et al. (2017), a importância da agricultura familiar sustenta-se nos seguintes aspectos: (a) a produção está intrinsecamente vinculada à segurança alimentar e nutricional, de forma a preservar os alimentos tradicionais e contribuir para uma alimentação balanceada e diversificada, garantindo a agrobiodiversidade e o uso sustentável dos recursos naturais; (b) potencial para geração de postos de trabalho e renda; c) representa uma oportunidade para impulsionar as economias locais, especialmente quando combinada com políticas específicas destinadas a promover a autonomia do agricultor, reafirmando sua identidade.

Embora haja o reconhecimento da importância dos agricultores familiares para com o desenvolvimento regional e social, diversas abordagens apresentam problemáticas e questões 
que dizem respeito à falta de valorização e inserção de parte dessa categoria em programas e ações de instituições, organizações e políticas públicas, refletindo em contextos que envolvem a posse e propriedade da terra, a baixa incorporação de tecnologias, a fragilidade da assistência técnica e extensão rural, bem como a dificuldade de acesso aos mercados (HEBERLÊ et al., 2017).

Segundo Medina (2016), um dos principais desafios enfrentados pelos agricultores familiares brasileiros está da porteira para fora, principalmente no acesso aos mercados, sendo que a comercialização assume um importante papel diante da atividade produtiva da agricultura familiar desenvolvida dentro da porteira. "A comercialização é uma atividade fundamental no processo de produção na agropecuária e assumir o protagonismo nessa fase permitiria capturar parte importante do valor gerado na atividade primária" (BELIK, 2017, p. 223).

Devido à relação que existe entre agricultores familiares com a ideia de segurança alimentar e nutricional, as compras institucionais representam uma nova oportunidade de acesso ao mercado, como a comercialização dos produtos agropecuários por meio do Programa Nacional de Alimentação Escolar (Pnae). Contudo esse Programa tem alguns desafios, como: a sensibilização dos consumidores, o assessoramento aos agricultores para que produzam de forma planejada e dentro das condições definidas pelos compradores, bem como a consolidação de organizações sociais (cooperativas e associações) (ALEXANDRE et al., 2016).

De acordo com Belik (2017), o alcance do Pnae tem sido limitado. Ainda são poucos os produtores que têm acesso a esses mercados de comercialização, seja pela baixa escala de produção, custos com transporte, preço e agregação de valor aos produtos, assimetria de informação e a falta de capacidade organizativa (SIEB, 2015).

Dessa forma, o presente artigo tem como objetivo verificar a inserção comercial da agricultura familiar no Pnae a partir dos preceitos propostos pela Nova Economia Institucional (NEI), com a finalidade de se compreender até que ponto esta é útil para se entender as questões e peculiaridades que envolvem os agricultores familiares, partindo da hipótese de que a agricultura familiar é uma categoria social que se constitui de uma família que trabalha em atividades agrícolas, com uma produção agroalimentar que é utilizada para o autoconsumo, mas também para a comercialização, inexistindo, na maioria das vezes, uma capacidade organizativa de acesso aos mercados que impulsione os agricultores familiares a comercializar a produção agropecuária via Pnae.

A partir dessa perspectiva e pela escassez de estudos nessa área, torna-se necessário compreender o Pnae como canal de acesso ao mercado pelos agricultores familiares, com o propósito de identificar suas limitações e também o processo de formação, implementação, bem como analisar esse Programa sob uma vertente econômica proposta pela NEI, por meio de ferramentas que permitam o desenvolvimento de um tipo de conhecimento próprio, que pode ser integrado em outros contextos, setores, permitindo uma ligação maior com os demais profissionais envolvidos na gestão do acesso ao mercado institucional.

\section{METODOLOGIA}

Dada a natureza deste estudo, foi utilizado o método dialético para seu desenvolvimento. Parte-se do entendimento de que, na natureza, tudo está relacionado, "para conhecer determinado fenômeno ou objeto, o pesquisador precisa estudá-lo em todos os seus aspectos, suas relações e conexões, sem tratar o conhecimento como algo rígido, já que tudo no mundo está sempre em constante mudança" (PRODANOV; FREITAS, 2013, p. 35). Dessa forma, foi 
analisado como os agricultores familiares têm acessado os mercados, com foco no Pnae, e os instrumentos propostos pela NEI, envolvendo fatores, principalmente, de ordem econômica e da sociologia rural.

Seguindo essa linha, foi utilizada uma abordagem qualitativa, com base na pesquisa bibliográfica, buscando descrever o problema, entender e verificar a importância dos instrumentos propostos pela NEI com a finalidade de aprimorar a concepção, gestão e operacionalização do Pnae. Para isso, foi analisada a porcentagem de aquisição da agricultura familiar via Pnae pelas escolas estaduais dos 21 (vinte e um) municípios do Território Médio Araguaia, GO, por meio das sedes das subsecretarias estaduais de educação nos municípios de Iporá, Piranhas e Jussara, nos anos de 2014 e 2015.

Escolheu-se esse território, localizado no estado de Goiás, e esses períodos, pois no ano de 2014 não havia nesse local a assessoria do Núcleo de Extensão em Desenvolvimento Territorial (Nedet), cenário diferente encontrado no ano de 2015, em que o Nedet passou a atuar. Assim, a partir do levantamento bibliográfico e por meio das informações obtidas, foi possível estabelecer uma relação entre as teorias que cercam a NEI e um maior acesso dos agricultores familiares de alguns municípios dessa região ao Pnae. Os dados do Pnae aqui utilizados foram coletados junto à Gerência de Alimentação Escolar da Secretaria Estadual de Educação de Goiás, e as percepções sobre as relações entre os agentes e seus respectivos comportamentos foram obtidas junto ao Nedet, já que no presente artigo um dos autores atuou como assessor territorial de inclusão produtiva (Atip) do referido núcleo.

Cabe ressaltar que, no presente estudo, quando se trata do comportamento dos agentes (racionalidade limitada e oportunismo de gestores de merenda das escolas, agricultores familiares, agentes das organizações como cooperativas etc.), não foi feita investigação profunda sobre o que determina tal comportamento, tampouco análise estatística sobre o quão recorrente é cada tipo de comportamento. A ocorrência de comportamento oportunista e de racionalidade limitada foi relatada pelos diversos agentes envolvidos no programa durante as sistemáticas entrevistas e reuniões realizadas pelo Nedet durante a sua assessoria às organizações do Território Médio Araguaia. Como é perceptível (a partir dos dados levantados) que as aquisições via Pnae foram insignificantes em 2014 e que apresentaram um grande salto em 2015, nota-se que entender o comportamento dos agentes na efetivação de políticas públicas é fundamental. E, para isso, a NEl pode contribuir sobremaneira na qualificação do acesso a tais políticas.

\section{RESULTADOS E DISCUSSÃO}

\subsection{Caracterizando os agricultores familiares}

Nas últimas décadas, embora o campo brasileiro tenha passado por diversas modificações, gerando uma intensa modernização e elevada produção e produtividade agropecuária, ainda existe uma grande parcela de produtores que enfrentam diversos problemas estruturais, tornando ineficiente a adoção de tecnologias, baixa produtividade, dificuldade de obtenção de crédito e de acesso aos mercados, entre outros aspectos que, consequentemente, intensificam a desigualdade existente no meio rural (VIEIRA FILHO; FISHLOW, 2017).

Essa grande parcela de produtores passou a ser definida e compreendida como agricultores familiares, marcados pela diversidade econômica e pela heterogeneidade social, o que dificulta sua delimitação conceitual. 
Segundo Altafin (2007), embora haja uma dificuldade em conceituar e delimitar esta categoria social, de modo geral, é possível destacar duas vertentes: uma que considera os agricultores familiares como consequência das transformações experimentadas pelas sociedades capitalistas, criados pelo Estado, por meio da implementação das políticas públicas, e a outra que defende ser a agricultura familiar um conceito em evolução, com significativas raízes históricas, intimamente ligados ao campesinato (ALTAFIN, 2007, p. 1).

Legalmente, o Decreto n. 9.064, que entrou em vigor em maio de 2017, além de dispor sobre a Unidade Familiar de Produção Agrária, instituiu o Cadastro Nacional da Agricultura Familiar, regulamentou a Lei n. 11.326, de 24 de julho de 2006, que estabelece as diretrizes para a formulação da Política Nacional da Agricultura Familiar e empreendimentos familiares rurais, e apresentou as características gerais necessárias para o reconhecimento do agricultor familiar e empreendedor familiar rural, sendo elas:

(I) Não detenha, a qualquer título, área maior do 4 (quatro) módulos fiscais;

(II) Utilize predominantemente mão de obra da própria família nas atividades econômicas do seu estabelecimento ou empreendimento;

(III) Tenha percentual mínimo da renda familiar originada de atividades econômicas do seu estabelecimento ou empreendimento; e

(IV) Dirija seu estabelecimento ou empreendimento com sua família (BRASIL, 2017).

Independentemente da linha conceitual adotada (teórica ou legal), essa categoria social sempre foi diferenciada no Brasil, com princípios e modo de vida próprios. Como regra geral, trata-se de um grupo de indivíduos que têm um pequeno pedaço de terra, "que trabalham mediante o uso da força de trabalho dos membros de suas famílias, produzindo tanto para seu autoconsumo como para a comercialização, e vivendo em pequenas comunidades ou povoados rurais" (SCHNEIDER; CASSOL, 2017, p. 84).

A agricultura familiar está relacionada diretamente às questões culturais, à segurança alimentar, à diversidade na produção, à preservação da agrobiodiversidade e, consequentemente, ao desenvolvimento local. Por possuir diversas características essenciais, os agricultores familiares conseguem gerar renda e trabalho, mesmo diante das dificuldades em acessar os mercados (ALTAFIN, 2007).

Assim, diferentemente do modo de produção empresarial, que se desenvolve a partir do uso de diversas tecnologias e com base na contratação de mão de obra, os agricultores familiares contam com a mão de obra da família como principal fator de produção, fazendo com que a unidade familiar tente buscar um equilíbrio entre trabalho e consumo, com o objetivo de satisfazer as suas necessidades. A partir do momento que o consumo não for atingido, haverá a necessidade de sobre-explorar a força de trabalho e, caso contrário, será adicionada uma força de trabalho cada vez menor (ABRAMOVAY, 1998).

Entretanto, ao comercializar a produção agropecuária, os agricultores familiares são obrigados a se inserirem no mercado, passando a competir com as empresas. Nessa competição, a unidade familiar teria de investir cada vez mais em trabalho para alcançar o mesmo nível de satisfação com o consumo, quebrando a lógica da economia familiar (MEDINA, 2016).

Nessa perspectiva, a inserção dos agricultores familiares em mercados alternativos e institucionais torna-se necessária com o propósito de evitar a competição direta com as empresas, aumentando a competitividade e promovendo o desenvolvimento econômico e social dessa categoria social. 


\subsection{MERCADOS E AGRICULTURA FAMILIAR}

É inegável que o agricultor familiar se insere nas cadeias do sistema agroalimentar que têm como protagonistas os grandes conglomerados agroindustriais. Mas o fortalecimento do setor varejista, representado pelas grandes redes de supermercados, alterou a configuração do mercado agroalimentar e colocou tanto a indústria de alimentos quanto os agricultores num papel secundário e com pouco poder de negociação. Dessa maneira, a agricultura familiar se vê num momento em que as possibilidades de comercialização se expandem via grandes mercados, porém essa modalidade de comercialização tem se mostrado excludente, pois demanda organização logística, padronização da qualidade e regularidade na oferta (WILKINSON, 2002).

A participação da agricultura familiar nos canais de comercialização do agronegócio pode trazer efeitos negativos no que se refere à manutenção de características básicas como a pluriatividade, a relativa autonomia e a capacidade de movimentação de mercados locais. Nesse sentido, "a agricultura familiar pode se tornar a vítima da receita comumente formulada para sua redenção" (MALUF, 2004, p. 302).

O surgimento de novos nichos de mercado e demandas por produtos diferenciados pode contribuir para o fortalecimento da agricultura familiar. Porém, dependendo da maneira como os agentes econômicos se envolvem no processo e do seu perfil, pode haver perdas em várias dimensões para as comunidades e unidades produtivas de base familiar (WILKINSON, 2002). Nesse sentido, surge o conceito de regionalização de circuitos comerciais, em que se aproveitam as sinergias dos diferentes agentes sociais, econômicos e produtivos, numa filosofia denominada "ganha-ganha", na qual a proximidade e o vínculo territorial e cultural podem gerar vantagens competitivas e produção com valor agregado (VAN DERPLOEG et al., 2000).

Formas alternativas de comercialização, como o comércio justo e a própria economia solidária, podem incorrer nos mesmos problemas do grande sistema agroalimentar, como a inserção de agentes e instituições alienígenas (perceptível no mercado que surgiu com o advento das certificações) (SABOURIN, 2013). Nessa perspectiva de risco de apropriação dessas novas tendências de inserção comercial da agricultura familiar por forças do grande agronegócio, o conceito de canais curtos de comercialização pode garantir que os ganhos econômicos e ambientais permaneçam nas comunidades e fortaleçam as economias locais (VAN DERPLOEG et al., 2000; MALUF, 2004).

O princípio da construção de mercados está baseado na inserção da agricultura familiar nos mercados agroalimentares por meio de estratégias autônomas que se adaptem à realidade dos agentes econômicos de pequeno porte. Nesse enfoque, consideram-se os mercados como resultado de construção social, o que cria outra lógica de definição de preços e padrões e pode unir diferentes agentes econômicos das cadeias (MALUF, 2004).

\subsection{Pnae (histórico, potenciais e gargalos)}

A primeira referência ao Programa Nacional de Alimentação Escolar (Pnae) surgiu na década de 1940 pelo Instituto de Nutrição, com a proposta do Governo Federal passar a oferecer alimentação às escolas, porém devido a falta de recursos, não foi possível executá-lo. Ao longo dos anos, essa política pública foi se estruturando e, atualmente o Pnae é operacionalizado pelas secretarias municipais e estaduais de educação (FNDE, 2018). 
Tanto as escolas estaduais quanto as secretarias municipais são obrigadas, por determinação legal, a adquirir no mínimo 30\% do recurso proveniente do Fundo Nacional de Desenvolvimento da Educação (FNDE) para o Pnae diretamente de agricultores familiares (FNDE, 2018).

Com o propósito de garantir a segurança alimentar e nutricional dos estudantes de toda a educação básica (educação infantil, ensino fundamental, ensino médio e educação de jovens e adultos) matriculados em escolas públicas, filantrópicas e em entidades comunitárias (conveniadas com o poder público) (FNDE, 2018), o PNAE representa uma nova oportunidade de mercado aos agricultores familiares.

Estudos realizados por Ciro e Freitas (2014), Alderete (2013), Ribeiro et. al (2013), entre outros, apresentam as mudanças provocadas pelo Pnae aos agricultores familiares, tais como: (I) acesso ao mercado institucional e à geração de renda, uma vez que o Pnae amplia as possibilidades de comercialização dos produtos advindos da agricultura familiar, ocasionando, consequentemente, um aumento na renda pelo maior volume de produtos vendidos e trazendo uma maior segurança aos agricultores pela garantia da comercialização; (II) fortalecimento da organização social dos agricultores em associações e/ou cooperativas, uma vez que a própria legislação destina mais recursos aos produtores que se encontram organizados; (III) diversificação da produção, uma vez que as escolas públicas aceitam e precisam de diversos produtos para montar os cardápios, e preocupação com o uso de insumos químicos no sentido de garantir a segurança alimentar e nutricional.

No entanto, apesar de o Pnae criar instrumentos de fortalecimento aos agricultores familiares por meio das compras públicas, esse Programa apresenta diversos gargalos. Segundo Belik (2017), o alcance do Pnae é limitado, ainda são poucos os produtores que têm acesso a esse programa de comercialização.

Além do reduzido número de agricultores familiares que participam do Pnae, a maioria desses não estão preparados e não têm produtos suficientes para abastecer essa política institucional. "Ao mesmo tempo, existem dificuldades em termos de documentação, de logística para o atendimento às grandes cidades, além de que os padrões de qualidade estabelecidos por muitas prefeituras dificultam uma maior inserção dos agricultores familiares" (STROPASOLAS, 2017, p. 451).

Para Alexandre et al. (2016), o Pnae apresenta desafios como a sensibilização dos consumidores, devendo a Secretaria Municipal de Educação (SME) e a Secretaria de Estado de Educação, Cultura e Esporte (Seduce) incluir produtos regionais e preparar as chamadas públicas para a realização das compras de alimentos, bem como a necessidade de um assessoramento técnico adequado, fazendo com que os agricultores familiares passem a produzir de forma organizada, planejada e dentro das condições delimitadas pelos compradores e pela legislação, uma vez que a limitação ou uma inadequada assistência técnica compromete o ambiente organizacional.

Assim, embora haja diversos gargalos e desafios a serem enfrentados, o Pnae não deixa de ser uma segurança aos agricultores familiares que utilizam os instrumentos de produção e comercialização desse Programa. 


\section{TERRITÓRIO MÉDIO ARAGUAIA E NÚCLEO DE EXTENSÃO EM DESENVOLVIMENTO TERRITORIAL (NEDET)}

O Território Rural Médio Araguaia, GO, localizado na região oeste do estado de Goiás, é composto por 21 municípios e tem 166.073 habitantes, sendo que 37.666 são da zona rural. Apesar de toda essa população rural, o território tem apenas 6.499 Declarações de Aptidão ao Pronaf (DAP), não possui convênios oficiais de prestação de serviço de assistência técnica e extensão rural (Ater) e, mesmo com essas dificuldades, movimentou na safra 2013-2014, via Programa Nacional de Fortalecimento da Agricultura Familiar (Pronaf), R\$ 45.920.915,03. A Figura 1 apresenta a localização do território dentro do estado de Goiás e a composição de municípios integrantes.

Figura 1 - Mapa do Território Rural Médio Araguaia, GO

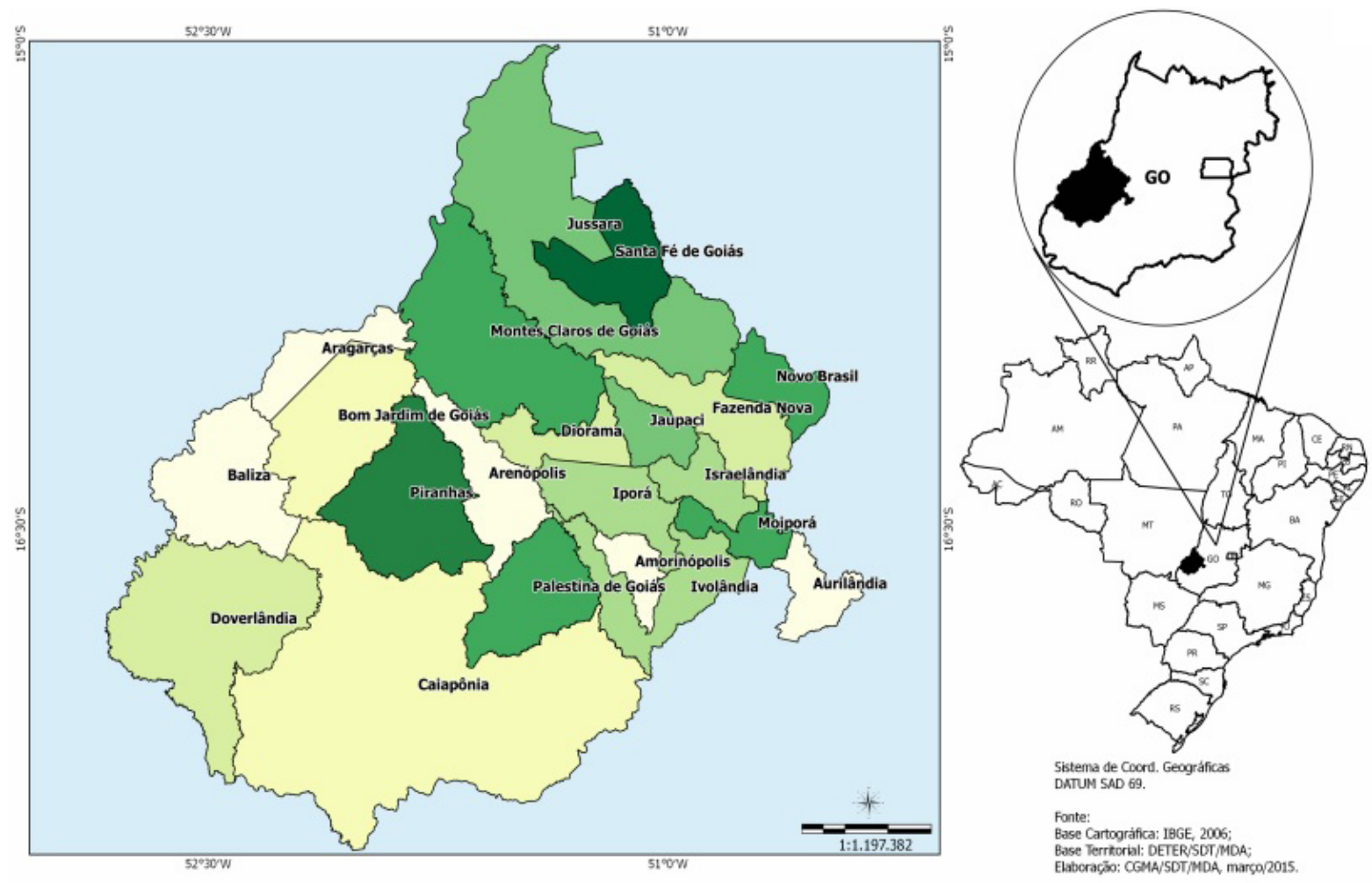

Fonte: MDA, 2015 (retirado da publicação Cadernos Territoriais da Secretaria de Desenvolvimento Territorial do Ministério do Desenvolvimento Agrário).

Dentro do território, é possível identificar três municípios de porte um pouco maior que os demais, que são considerados pela população como polos microrregionais. São eles: Iporá, Jussara e Piranhas. De alguma forma, todos os municípios do território têm alguma ligação com algum desses três municípios. São nesses que estão as agências bancárias dos principais bancos, subsecretarias de educação estadual, instituições de ensino superior, feiras e mercados.

No ano de 2015, o Território Médio Araguaia recebeu um apoio da Universidade Federal de Goiás, por meio de convênio com o Ministério do Desenvolvimento Agrário e através da implementação do programa de Núcleos de Extensão em Desenvolvimento Territorial (Nedets), que se baseou na assessoria em inclusão produtiva e gestão social. Os Nedets referem-se a unidades administrativas que têm a finalidade de apoiar ações de extensão e de assessoramento 
técnico aos Colegiados Territoriais e demais atores dos territórios rurais, como estratégia de fortalecimento e consolidação da abordagem territorial da Secretaria de Desenvolvimento Territorial (SDT) (UFG, 2018).

Tal convênio teve vigência até outubro de 2016 e, por meio da atuação na assessoria de inclusão produtiva, foi possível perceber algumas potencialidades e dificuldades da agricultura familiar no que tange a sua inserção às diversas modalidades de comercialização (mercado institucional, mercado convencional, feiras livres, feiras da agricultura familiar, mercado do leite, entre outros).

A partir das percepções e dos dados levantados durante a assessoria ao território, foi detectada a necessidade de se fazer projetos de pesquisa capazes de gerar informações que auxiliem os agricultores a potencializar seu acesso aos diferentes canais de comercialização.

\section{ANÁLISE DAS TRANSAÇÕES DO PNAE NOS MUNICÍPIOS DO TERRITÓRIO MÉDIO ARAGUAIA SOB A LENTE METODOLÓGICA DA NEI}

A partir dos dados obtidos nos anos de 2014 e 2015, expressos no Gráfico 1, referentes às aquisições de alimentos oriundos da agricultura familiar efetuadas pela Secretaria Estadual de Educação, Cultura e Esporte do Estado de Goiás (Seduce), via Pnae, nos municípios integrantes do Território Rural Médio Araguaia, é possível ao menos sugerir que, quando as organizações da agricultura familiar recebem algum tipo de assessoria pública, conforme ocorreu no ano de 2015, há maiores possibilidades de acessarem os mercados institucionais.

Gráfico 1 - Gastos das Subsecretarias Estaduais de Iporá, Jussara e Piranhas em 2014 e 2015

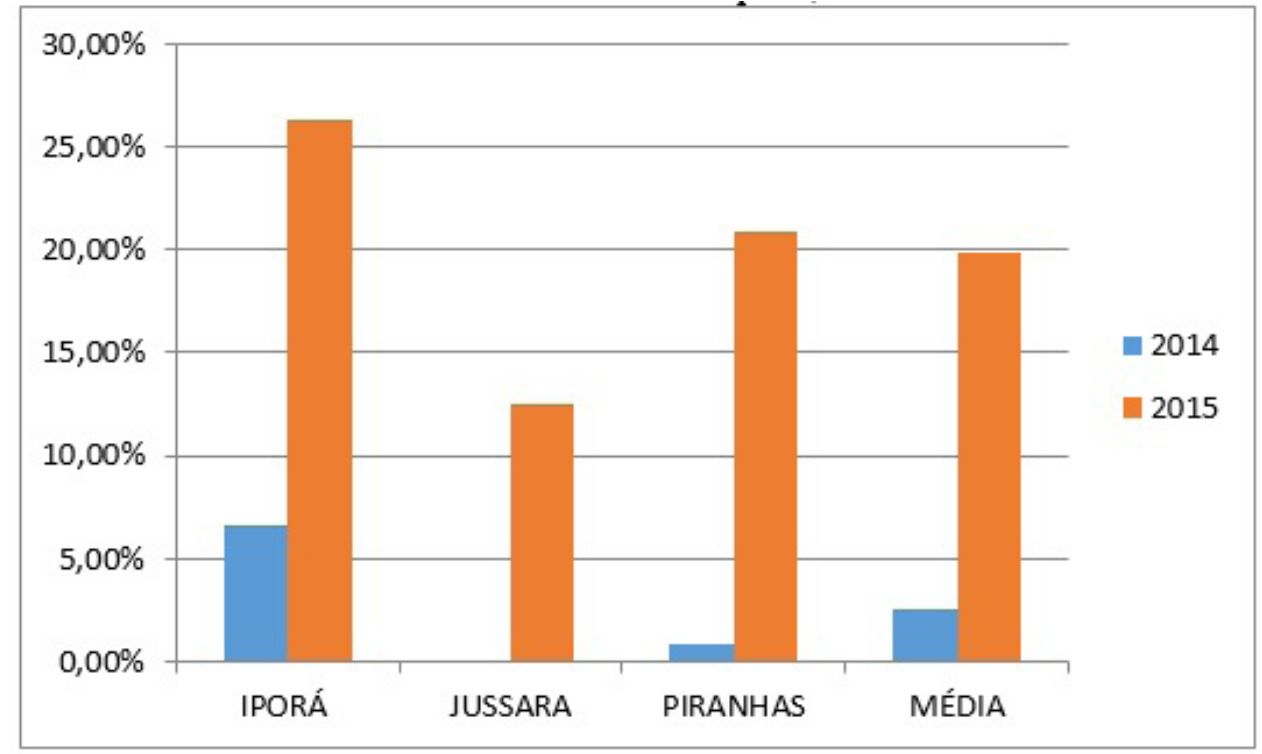

*As escolas estaduais dos 21 municípios do território estão integradas a alguma dessas Subsecretarias.

Fonte: Gerência de Alimentação Escolar (Secretaria Estadual de Educação, Cultura e Desporto, $\mathrm{GO})$. 
O presente artigo não tem o objetivo de analisar estatisticamente tais dados, optamos por compreender os processos de transação sob a lente metodológica da Nova Economia Institucional, tendo como recorte o Pnae no Território Médio Araguaia. Vale destacar que as relações que serão levantadas foram observações empíricas, não sendo sistematizadas com o rigor científico, oriundas dos relatórios de atividades dos assessores do Núcleo de Extensão em Desenvolvimento Territorial. Porém tais observações poderão servir de base para futuras pesquisas, não sendo objetivo deste artigo definir conclusões assertivas.

Embora a Nova Economia Institucional (NEI) seja orientada por uma perspectiva econômica, seus conceitos, teorias, podem ser explorados por diferentes áreas, no sentido de explicar o papel das instituições e das organizações em uma determinada atividade, com o propósito de que essas reduzam as incertezas nas trocas.

Em oposição à teoria neoclássica, que defende mercados perfeitos, a racionalidade dos agentes e a informação completa, os teóricos da NEl acreditam que, no mundo real, as informações são limitadas, incompletas, podendo gerar o oportunismo.

a) Racionalidade limitada e oportunismo dos agentes

Os agentes econômicos, ao buscarem atender seus interesses, não conseguem obter as informações necessárias ou não têm a capacidade de processamento e articulação das informações disponíveis para a realização das transações no mercado, pelo fato de essas serem limitadas, não sendo possível prever todos os acontecimentos que envolvem as transações ou, ainda, antecipar todos os eventos que podem suscitar a necessidade de correções nas condutas das partes (PONDÉ, 2007).

Além das informações serem limitadas, elas podem também ser disponibilizadas de forma ineficientes, incompletas ou distorcidas, gerando o oportunismo. O oportunismo associa-se à incerteza vinculada ao comportamento de agentes individuais, que podem atuar buscando seus próprios interesses de modo a confundir, enganar, antes ou até mesmo durante uma transação acordada (CONCEIÇÃO; COSTA, 2006).

Ao relacionar a racionalidade limitada e o oportunismo dos agentes com o objeto de estudo, verifica-se que, apesar de ser obrigatório que toda escola pública adquira no mínimo $30 \%$ dos alimentos utilizados nas refeições dos alunos da agricultura familiar, nota-se que em nenhum dos dois anos analisados a cota mínima foi alcançada. A racionalidade limitada dos agentes pode ser um dos motivos desse problema.

Antes de iniciar a análise, vale destacar que, no universo da agricultura familiar camponesa, a racionalidade econômica não pode ser pensada separadamente da racionalidade ambiental ou da racionalidade referente à penosidade do trabalho. Ademais, o tema da racionalidade limitada está mais ligado à dificuldade de alguns gestores das escolas entenderem que, ao comprar produtos da agricultura familiar, estarão fomentando o desenvolvimento da economia local, estarão adquirindo alimentos produzidos e processados localmente e com maior possibilidade de serem mais saudáveis e sustentáveis, entre outros aspectos.

Mas a racionalidade limitada desses se inicia no momento em que ele desconhece que existe produção de alimentos nas comunidades locais e, em vez de adquirir produtos da agricultura familiar camponesa, emite uma justificativa para a Gerência de Merenda Escolar, alegando que não houve interesse de nenhum agricultor em participar da chamada pública.

Essa questão também pode ser analisada por meio de outro aspecto da NEl: o oportunismo. Alguns gestores de escolas, por questões políticas ou pela cultura do apadrinhamento e 
clientelismo, preferem comprar todo o alimento da escola no mercado convencional do município (onde grande parte dos produtos são oriundos do Ceasa). Mas como isso é possível? Duas possibilidades que podem ser explicadas pelo oportunismo são levantadas: (1) o proprietário do mercado local obtém uma DAP de algum agricultor familiar conhecido e, por meio desse documento, participa das chamadas públicas; ou (2) o gestor da escola não se compromete em envolver as organizações e comunidades locais antes de proceder a chamada pública, resultando na não participação delas na concorrência e, consequentemente, na elaboração por parte da escola de uma justificativa para não adquirir produtos da agricultura familiar.

Porém o fato da quantidade de compra de alimentos da agricultura familiar ter apresentado um salto entre 2014 e 2015 leva a crer que o principal gargalo na operacionalização do Pnae (quando se trata do comportamento dos agentes) é a racionalidade limitada, e não o comportamento oportunista. Ou seja, quando houve um estímulo e acompanhamento por parte do Nedet à operacionalização do Pnae, tal política apresentou avanços, pois os assessores contribuíram na articulação dos diversos agentes envolvidos no Programa. Isso leva a crer que a falta de informações (tanto dos gestores de merenda quanto dos agricultores familiares) é o que mais pesa na operacionalização da política, e não o comportamento oportunista.

Assessores do Nedet também relataram que, a partir das reuniões e entrevistas com os diversos agentes ligados às escolas estaduais, foi possível observar comportamento oportunista em algumas organizações de agricultores familiares e em alguns agricultores familiares, tais como: (1) não cumprimento do contrato no que se refere aos prazos de entrega e às variedades requeridas pela escola; (2) entrega de produtos sem qualidade ou fora do padrão; (3) atuação de agricultores como atravessadores, que, em vez de produzir, compram no mercado convencional e vendem para a escola.

Apesar de, no ano de 2015, também não ter chegado à meta de $30 \%$, é evidente que o Pnae demonstrou avanços. Esse avanço se deve também ao processo de assessoria que a Universidade Federal de Goiás (UFG) prestou às organizações da agricultura familiar, servindo como interlocutora entre as organizações da sociedade civil e do poder público. Tal interlocução contribuiu sobremaneira para diminuir a limitação da racionalidade dos agentes, pois os aproximou e ampliou o acesso às informações. Com isso, os gestores das escolas puderam formular cardápios com produtos passíveis de serem ofertados pela agricultura familiar, e as organizações dos agricultores puderam ter acesso às informações referentes às chamadas públicas.

A assessoria também logrou êxito no que tange à diminuição do comportamento oportunista, pois divulgou massivamente entre os diversos grupos e organizações dos municípios o papel do Pnae e sua relevância econômica, social e cultural. Assim, os gestores se viram na obrigação de cumprir a lei e os agricultores entenderam a importância de cumprir de forma correta os contratos, uma vez que a sociedade como um todo estava envolvida no processo, aumentando o controle social das transações.

b) Assimetria de informação entre e dentro das organizações

De acordo com a NEl, a assimetria de informação que existe entre e dentro das organizações refere-se a uma falha de mercado, criando dificuldades para que os agentes econômicos obtenham informações relevantes sobre as transações no mercado, sobre as cláusulas contratuais ou riscos de inadimplência, influenciando significativamente e determinando os custos de transação.

Nesse sentido, "as incertezas são originadas da complexidade das relações e da informação incompleta - assimetria de informação - relativa ao comportamento dos agentes econômicos ao 
longo de um processo produtivo" (SIMAN et al., 2006, p. 40) e, ao analisar o desenvolvimento e os desdobramentos do Pnae nos municípios do Território Médio Araguaia, é possível perceber que a assimetria de informação está presente em várias etapas e dimensões do processo. Essa assimetria é perceptível, tanto entre as organizações (associações, cooperativas, escolas, conselhos de alimentação escolar, Agência de Assistência Técnica, Extensão Rural e Pesquisa Agropecuária [Emater] etc.), quanto dentro delas, gerando impasses e gargalos que foram (em certa medida) superados a partir da assessoria do Nedet.

De acordo com relatos de agricultores, há municípios em que alguns gestores estão tão acostumados a comprar os alimentos apenas do mercado convencional local, que nem sabem qual o leque de produtos produzidos pela agricultura familiar do município. Ou seja, uma parcela de gestores não compreende que essa prática, além de ser ilegal, favorece a concentração econômica do município e impede a inclusão produtiva e social dos agricultores e suas respectivas organizações. No caso do Pnae na rede pública estadual, existe mais um problema referente à elaboração dos cardápios.

O profissional de nutrição que elabora os cardápios na Gerência Estadual de Alimentação Escolar não é concursado (o que gera grande rotatividade e baixo acúmulo de informações sobre as ofertas de produtos de cada região), e ele, sozinho, é responsável pela elaboração do cardápio de todas as escolas do estado. Além disso, tal profissional reside em Goiânia e conta com poucos recursos para acompanhar as elaborações de cardápio e chamadas públicas de cada subsecretaria.

Assim, na prática, o nutricionista apenas aprova os cardápios elaborados pelos gerentes de merenda de cada escola. Não há trocas de informações referentes às características de produção de cada região entre as Ematers, nutricionistas, gerentes de merenda das escolas e organizações da agricultura familiar.

A assimetria de informação também ocorre dentro das instituições. Muitos agricultores familiares se queixam por não receber das direções de suas associações e cooperativas informações referentes a datas de plantio, formas de escalonamento da produção e boas práticas de colheita e transporte. Ou seja, algumas cooperativas e associações só entram em contato com os agricultores na época que as escolas estão demandando o produto, e o ideal seria que o processo de comunicação entre diretoria e base se desse ao longo de todo o processo. A atuação do Nedet teve a importante função de nivelar as informações entre esses diversos agentes, o que resultou no grande salto de transações de 2014 para 2015.

c) Custos de transação

Para se efetivar a comercialização dos produtos da agricultura familiar via Pnae, é necessário todo um trabalho anterior que pode ser analisado sob a ótica da economia dos custos de transação. Os custos de transação nada mais são do que as despesas que os agentes econômicos enfrentam quando se inserem no mercado, seja para a compra, seja para a venda. Segundo Conceição e Costa (2006, p. 2), "os custos de transação podem ser vistos como aqueles não diretamente relacionados às formas pelas quais as transações econômicas são processadas", como os custos com negociação, elaboração e garantia de cumprimento de um contrato, no sentido de reduzir as incertezas e, consequentemente, as assimetrias de informação.

Tais custos podem ser divididos de acordo com a sua fase de comercialização da seguinte forma: custos de preparação; custos de negociação; custos de controle e custos de adaptação.

Pelo lado dos agricultores, podemos identificar os custos de transação de preparação, como o tempo gasto pelas organizações da agricultura familiar em articular junto aos gestores 
escolares uma chamada pública que demande produtos feitos na região, além da elaboração das propostas que concorrerão nas chamadas e do processo de levantamento de informações referentes a tipos e volume de produtos junto aos agricultores de cada organização.

Pelo lado da escola, podemos identificar como custo de transação de preparação o processo de levantamento de informações acerca das organizações (formais e informais) da agricultura familiar presentes em sua região e os tipos e volumes de alimentos produzidos em cada época do ano.

Os custos de transação de negociação nas vendas/compras feitas via Pnae vão além dos custos referentes ao estabelecimento de contratos. Apesar de o cardápio de cada escola ser feito semestralmente, o processo de alimentação escolar é bastante complexo e dinâmico, o que, em muitos casos, leva os gestores de merenda a demandarem algum produto que não esteja "oficialmente" no contrato.

Da mesma forma, os agricultores familiares em alguns momentos (de perdas de safra ou aumento súbito no preço dos insumos), por não terem o produto especificado no contrato, acabam negociando a oferta de algum outro para substitui-lo. Os custos de transação de controle são um grave gargalo do Pnae. Em alguns municípios do Território Médio Araguaia, detectouse que as escolas não compravam da agricultura familiar, pois tiveram experiências anteriores negativas, tais como baixa qualidade do produto, falta de organização na periodicidade de entrega e alteração de preços após o estabelecimento do contrato. Pelo lado da agricultura familiar, foi detectado que algumas escolas também falhavam na organização do recebimento dos produtos e na formulação dos pedidos, gerando custos adicionais referentes a transporte e logística.

Por fim, em se tratando dos custos de adaptação, podemos levantar a hipótese de que algumas escolas não adquirem a cota mínima de 30\% da agricultura familiar, pois o custo de transação para se efetivar uma compra da agricultura familiar é maior do que para se efetivar uma compra do mercado convencional local, bem como, para alguns agricultores familiares, atuar nesse canal de comercialização pode não ser muito atraente devido à demanda, por parte das escolas, de uma periodicidade de entrega muito alta e uma quantidade de produtos por entrega muito baixa. A partir dessa hipótese, é possível detectar uma possível limitação da NEI que se refere à dificuldade em se analisar algumas especificidades de processos de comercialização alternativos ao modelo hegemônico.

Os mercados institucionais podem ser considerados alternativos ao modelo hegemônico, pois não estão ancorados nas leis de oferta e procura e visam proteger segmentos econômicos fragilizados pela competitividade do mercado agrícola. Ou seja, as abordagens que explicam os mercados convencionais são insuficientes para explicar os mercados alternativos, pois nem tudo é valorado de forma pecuniária.

d) Especificidade dos ativos

Uma das principais características das transações é a especificidade de ativos. Os ativos específicos, por sua vez, são irrecuperáveis, no sentido de que não podem ser reempregáveis em outra transação sem perda de valor. Além disso, os ativos específicos fazem com que a identidade dos envolvidos na transação, assim como a continuidade dos vínculos estabelecidos entre esses, intensifique-se, deixando de ser impessoal e instantânea, acarretando custos para geri-las e conservá-las (PONDÉ, 2007).

No que se refere aos processos de comercialização dos produtos da agricultura familiar via Pnae, o tema da especificidade dos ativos pode ser abordado de forma superficial, já que 
não cabe nessa modalidade de comercialização (de acordo com a legislação) terceirizar alguma etapa da produção.

Por outro lado, a verticalização pode ser encarada como a possibilidade de agregar valor ao produto (por exemplo, vender a polpa da fruta em vez de vender a fruta in natura). Mas a discussão sobre a especificidade dos ativos no caso do Pnae vai no sentido de se pensar esse mercado como uma modalidade de comercialização específica, em que as relações de compra e venda não se dão da mesma forma que no mercado convencional. As escolas, em tese, não têm a possibilidade de não comprar da agricultura familiar, e por isso não existe uma concorrência plena. Assim, detectamos mais uma fragilidade da NEI em se analisar mercados específicos (seja pela regionalização, seja pela proteção de políticas públicas).

e) Contratos

Como visto acima, de acordo com a NEI, temos a racionalidade limitada, o oportunismo e a especificidade de ativos. Em razão desses fatores e da assimetria de informações, é necessário adotar medidas para salvaguardar as transações e mitigar os custos de transação. Um importante instrumento que pode ser adotado são os contratos. São esses que permitem a organização interna das firmas, bem como garantem a execução da transação, evitando o oportunismo.

Pensando na diminuição dos riscos, as firmas tendem a elaborar contratos cada vez maiores e mais específicos. Talvez essa seja uma das deficiências dos contratos estabelecidos nas transações do Pnae. Segundo Conceição e Costa (2006, p. 3), a elaboração de um contrato "não é uma tarefa simples, ao contrário, é complexa e demorada; para que um contrato seja estabelecido é necessário que haja uma configuração favorável para reduzir os custos (essencialmente os de transação), os riscos de comportamento oportunista e as incertezas".

Grande parte dos contratos estabelecidos entre as escolas e as organizações da agricultura familiar do Território Médio Araguaia são meras cópias de modelos sugeridos pela Seduce. Isso pode ser o reflexo de dois aspectos: (1) A relação de proximidade e confiança entre as escolas e as comunidades que fornecem os alimentos é muito grande e não é interessante para nenhuma das partes (já que existe a possibilidade de transações futuras) práticas desonestas.

Assim, os contratos formais são apenas um meio de oficializar um processo que tem sua fundamentação muito mais ligada a aspectos de confiança e reciprocidade do que em aspectos legais; (2) a falta de pessoas capacitadas tanto nas escolas quanto nas organizações da agricultura familiar reflete na execução de transações pouco profissionais e, consequentemente, na formulação de um contrato frágil.

Entendendo essa complexidade das relações que refletem na elaboração de contratos frágeis, o Nedet assessorou tanto na elaboração de contratos mais específicos quanto na aproximação escola/agricultor familiar. Isso gerou maior confiança por parte dos gestores das escolas no profissionalismo dos agricultores, refletindo no aumento significativo das vendas via Pnae do Território Médio Araguaia.

f) Estrutura de governança

A estrutura de governança está relacionada com a forma como as atividades econômicas em todo seu conjunto (regimento interno, contratos entre as unidades econômicas) são coordenadas, podendo ser definida a partir das características das diferentes transações, quer seja por meio da incerteza, quer seja por meio da frequência e da especificidade dos ativos, no 
sentido de diminuir os custos de transação, diminuindo o oportunismo e as falhas contratuais (SACOMANO NETO; TRUZZI, 2002).

Assim, "a estrutura de governança determinante das relações entre os agentes deve ser adequada aos atributos da transação, levando-se em conta o arranjo institucional vigente" (LEITÃO et al., 2008, p. 4), uma vez que, quanto mais adequada for a estrutura de governança, mais forte será a relação entre o ambiente institucional e a coordenação da cadeia.

É clara a relação entre as dificuldades de acesso dos agricultores familiares ao Pnae e os problemas relacionados às estruturas de governança tanto das organizações da agricultura familiar quanto das outras instituições que operam e atuam em tal programa. No Território Médio Araguaia, foram observados alguns aspectos nesse sentido, tais como: a) distanciamento entre diretoria das cooperativas da agricultura familiar e suas respectivas bases, o que gera dificuldade em se aferir a produção e, consequentemente, ofertar os produtos demandados pelas escolas; b) as subsecretarias estaduais de educação não têm em sua estrutura pessoas capacitadas para atuar na interlocução com as comunidades do território, o que gera a elaboração de cardápios que não condizem com a realidade produtiva da região (um exemplo seria a inserção de frutos como maçã e pera, que não são produzidos no território). A atuação do Nedet teve um papel relevante na transformação dessa realidade, pois, apesar de não ter sido proposta alteração nas estruturas de governança das instituições, foi feito um trabalho de aproximação entre os diversos agentes do processo, gerando maior clareza das atribuições de cada instituição e ator que atua no Pnae.

\section{CONSIDERAÇÕES FINAIS}

Levando em consideração os resultados das análises feitas sobre os agricultores familiares e sua inserção nos mercados; o Pnae, com seus potenciais e gargalos; a política territorial, Território Médio Araguaia e Nedet, como formas de potencializar o acesso às políticas públicas; e a análise das transações do Pnae nos municípios do Território Médio Araguaia sob a lente metodológica da NEl, foi possível verificar que as políticas públicas de assessoria às organizações da agricultura familiar (no caso analisado, o Nedet) são importantes para a efetivação da inclusão produtiva dos agricultores familiares. Analisando esse processo sob a lente metodológica da Nova Economia Institucional, é possível problematizar as transações com uma maior acurácia do que a análise sob a ótica neoclássica. Porém a NEI ainda não é suficiente para decifrar nuances específicas da agricultura familiar, pois a lógica produtiva desse grupo não é estritamente econômica e perpassa questões culturais, sociais, ambientais e de cunho familiar.

Assim, é possível afirmar que a NEI oferece ferramentas metodológicas importantes, mas ainda insuficientes para se compreender a agricultura familiar e seus processos de comercialização, especificamente o Pnae.

\section{REFERÊNCIAS}

ABRAMOVAY, Ricardo. Paradigmas do capitalismo agrário em questão. 2. ed. São Paulo: Hucitec; Campinas: Ed. Unicamp, 1998.

ALEXANDRE et al. Passos da comercialização pelo Programa Nacional de Alimentação Escolar (PNAE) e pelo Programa de Aquisição de Alimentos (PAA). In: AGRICULTURA Familiar em Goiás: lições para assessoramento técnico. 3. ed. rev. e ampl. Goiânia: Editora UFG, 2016. 
ALDERETE, Luis Humberto Pinto. A contribuição do Programa Nacional de Alimentação Escolar (PNAE) no município de Maçambará/RS. 2013. 46 f. Trabalho de Conclusão de Curso (Graduação Tecnológica em Desenvolvimento Rural) - Universidade Federal do Rio Grande do Sul, Itaqui, RS, 2013. Disponível em: http://www.lume.ufrgs.br/bitstream/handle/10183/87415/000908175.pdf?sequence=1. Acesso em: 29 dez. 2017.

ALTAFIN, lara. Reflexões sobre o conceito de agricultura familiar. Brasília: CDS/UnB, 2007. Disponível em: http://www.enfoc.org.br/web/arquivos/documento/70/f1282reflexoes-sobre-o-conceito-de-agricultura-familiar-iaraaltafin---2007.pdf Acesso: 27 dez. 2017.

BELIK, Walter. Circuitos de agricultura familiar no Brasil: notas para discussão in Agricultura Familiar Brasileira- desafios e perspectivas de futuro. Brasília: Ministério do Desenvolvimento Agrário, 2017.

BRASIL. Decreto n. 9.064, de 31 de maio de 2017. dispõe sobre a Unidade Familiar de Produção Agrária, institui o Cadastro Nacional da Agricultura Familiar e regulamenta a Lei n. 11.326, de 24 de julho de 2006, que estabelece as diretrizes para a formulação da Política Nacional da Agricultura Familiar e empreendimentos familiares rurais. Brasília-DF, 2017. Disponível em: www.planalto.gov.br/ccivil_03/_Ato2015-2018/2017/Decreto/ D9064.htm. Acesso em: 27 dez. 2017.

BRASIL. Ministério do Desenvolvimento Agrário. Secretaria de Desenvolvimento Territorial. Cadernos Territoriais, Brasília-DF, 2015.

BRASIL. Lei n. 11.326, de 24 de julho de 2006. Estabelece as diretrizes para a formulação da Política Nacional da Agricultura Familiar e Empreendimentos Familiares Rurais. Brasília-DF, 2006. Disponível em: http://www. planalto.gov.br/ccivil_03/_ato2004-2006/2006/lei/l11326.htm. Acesso em: 15 out. 2018.

CIRO, Paulo Marcos dos Reis; FREITAS, Alan Ferreira de. O Programa Nacional de Alimentação Escolar como indutor de processos de desenvolvimento local em Viçosa (MG). Espaço do Produtor, 21 ago, 2014. Disponível em: https://www2.cead.ufv.br/espacoProdutor/scripts/verArtigo.php?codigo=41\&acao=exibir. Acesso em: 29 dez. 2017.

CONCEIÇÃO, Ronald Jesus; COSTA, Armando João Dalla. Custos de transação e estruturas organizacionais: um estudo de caso para o setor petrolifero. In: SIMPÓSIO DE ENGENHARIA DE PRODUÇÃO, 13., 6 a 8 de novembro de 2006, Bauru, SP. Anais [...]. São Paulo: SIMPEP, 2006.

FUNDO NACIONAL DE DESENVOLVIMENTO DA EDUCAÇÃO. Programa Nacional de Alimentação Escolar - Sobre o Pnae. Brasília-DF: Miniostério da Educação, [s.d.]. Disponível em: http://www.fnde.gov.br/programas/ pnae/pnae-sobre-o-programa/pnae-sobre-o-pnae. Acesso em: 2018.

HEBERLÊ, Antônio Luiz Oliveira et al. Agricultura familiar e pesquisa agropecuária: contribuições para uma agenda de futuro. In: AGRICULTURA familiar brasileira: desafios e perspectivas de futuro. Brasília: Ministério do Desenvolvimento Agrário, 2017. p.__-_.

IBGE. Censo Agropecuário de 2006. Agricultura familiar. Rio de Janeiro, 2009.

LEITÃO, Fabrício Oliveira et al. Análise sob a ótica da NEI/ECT das estruturas de governança na cadeia produtiva da ovinocaprinocultura no Distrito Federal. In: Sociedade Brasileira de Economia, Administração e Sociologia Rural. Rio Branco, Acre, 20 a 23 de julho de 2008. Anais[...]. Rio Brando, 2008.

MALUF, Renato. Mercados agroalimentares e a agricultura familiar no Brasil: agregação de valor, cadeias integradas e circuitos regionais. Ensaios FEE, v. 25, 2004.

MEDINA, Gabriel. Agricultura familiar em Goiás: lições para o assessoramento técnico. 3. ed. rev. e ampl. Goiânia: Editora UFG, 2016. 
PONDÉ, João Luiz. Nova economia institucional. FGV: Direito Rio, 2007.

PRODANOV, Cleber Cristiano; FREITAS, Ernani Cesar. Metodologia do trabalho científico. 2. ed. Novo Hamburgo, RS: Feevale, 2013.

RIBEIRO, Ana Lúcia de Paula et al. Programa Nacional de Alimentação Escolar (PNAE) e a participação da agricultura familiar em municípios do Rio Grande do Sul. Revista Gestão e Desenvolvimento em Contexto - Gedecon, v. 1, n. 1, 2013.

SABOURIN, Eric. Comercialização dos produtos agrícolas e reciprocidade no Brasil. Estudos Sociedade e Agricultura, v. 21, n. 1, 2013.

SACOMANO NETO, Mário; TRUZZI, Oswaldo Mário Serra. Perspectivas Contemporâneas em Análise Organizacional. Gestão \& Produção, v. 9, n. 1, p. 32-44, abr. 2002.

SCHNEIDER, Sergio; CASSOL, Abel. Diversidade e heterogeneidade da agricultura familiar no Brasil e implicações para políticas públicas. In: AGRICULTURA familiar brasileira: desafios e perspectivas de futuro. Brasília: Ministério do Desenvolvimento Agrário, 2017.

SIEB, Décio Lauri. Estratégias de comercialização: o caso dos agricultores familiares do assentamento Rio Paraíso - município de Jataí (GO). Dissertação (Mestrado em Agronegócios)- Universidade de Brasília (UnB), Brasília-DF, 2015.

SIMAN, Renildes Fortunato et al. A economia institucional: em busca de uma teoria do desenvolvimento rural. Perspectiva Econômica, v. 2, n. 2, p. 37-55, jul./dez. 2006.

STROPASOLAS, Valmir Luiz. Tecendo os fios condutores de um debate: que desafios, perspectivas e proposições para as agriculturas de base familiar e camponesa do Brasil? In: AGRICULTURA familiar brasileira: desafios e perspectivas de futuro. Brasília: Ministério do Desenvolvimento Agrário, 2017.

Universidade Federal de Goiás. NEDET. Jataí, [s.d.]. Disponível em: https://neaf.jatai.ufg.br/p/19017-nedet. Acesso em: 15 out. 2018.

VAN DERPLOEG, J., RENTING, H., BRUNORI, G., KNICKEL, K., MANNION, J., MARSDEN, T. From practices and policies towards theory. Sociologia Ruralis, v. 40, n. 4, p. 391-408, 2000.

VIEIRA FILHO, José Eustáquio Ribeiro; FISHLOW, Albert. Agricultura e indústria no Brasil: inovação e competitividade. Brasília: Ipea, 2017.

WILKINSON, John. Os gigantes da indústria alimentar entre a grande distribuição e os novos clusters a montante. Estudos Sociedade e Agricultura, v. 18, 2002.

WANDERLEY, Maria de Nazareth Baudel. "Franja Periférica", "Pobres do Campo", "Camponeses": dilemas da inclusão social dos pequenos agricultores familiares. In: AGRICULTURA Familiar Brasileira: desafios e perspectivas de futuro. Brasília: Ministério do Desenvolvimento Agrário, 2017.

\section{Sobre os autores:}

Fernanda Chaveiro da Silva: Doutoranda e Mestre em Agronegócio pela Universidade Federal de Goiás (UFG). Especialista em Direito Civil e Empresarial, e graduada em Direito pela Pontifícia Universidade Católica de Goiás (PUC Goiás). Desenvolve trabalhos sobre o sistema jurídico e a atividade agropecuária, sustentabilidade, meio ambiente, direito agrário. E-mail: fernandachaveiro89@hotmail.com, Orcid: https://orcid.org/0000-0001-6219-307X 
Thiago de Carvalho Verano: Mestrando em Agronegócio pela Universidade Federal de Goiás (UFG). Especialista em Agricultura Familiar Camponesa e Educação do Campo e graduado em Agronomia pela UFG. Experiência profissional na área de extensão em comunidades camponesas e organizações de agricultores com foco em agroecologia, políticas públicas e canais de comercialização da agricultura familiar camponesa. E-mail: veranoseco@gmail.com, Orcid: https://orcid.org/0000-0002-5767-0414

Cleyzer Adrian da Cunha: Pós-doutor em Economia pela Fundação Getulio Vargas (FGV). Doutor em Economia Aplicada pela Universidade Federal de Viçosa (UFV). Mestre em Economia Aplicada pela UFV. Graduado em Economia pela Pontifícia Universidade Católica de Minas Gerais (PUC Goiás). Professor associado de Teoria Econômica na Universidade Federal de Goiás (UFG). E-mail: cleyzercunha@gmail.com, Orcid: https://orcid.org/0000-0003-1650-699X

Alcido Eleonor Wander: Doutor em Ciências Agrárias (Concentração: Economia Agrícola) pela Georg August Universität Göttingen, Alemanha. Mestre em Ciências Agrárias dos Trópicos e Subtrópicos pela Georg August Universität Göttingen. Graduado em Agronomia pela Universidade de Kassel, Alemanha. Pesquisador da Empresa Brasileira de Pesquisa Agropecuária (Embrapa), professor dos Programas de Pós-Graduação em Agronegócio da Universidade Federal de Goiás (UFG). E-mail: alcido.wander@embrapa.br, Orcid: https://orcid.org/0000-0001-9656-8773 